\title{
HYPOLIPIDEMIC AND ANTI-OXIDANT EFFECT OF PERSIA AMERICANA AQUEOUS LEAF EXTRACT ON WISTAR RATS
}

\author{
'E. N. Ekene., 2 L. U. Nwankwo and ${ }^{3}$ A. J. Uyovwiesevwa
}

'Department of Pharmacology, Faculty of Basic Medical Sciences, College of Health Sciences, Delta State University, Abraka, Delta State, Nigeria.

\begin{abstract}
2Department of Pharmacognosy, Faculty of Pharmacy, Delta State University, Abraka, Delta State, Nigeria
3Department of Human Physiology, Faculty of Basic Medical Sciences, Delta State University, Abraka, Delta State, Nigeria
\end{abstract}

Email: osgiedeprof@yahoo.com

(Received on Date: 17 th June 2020 Date of Acceptance: 22 ${ }^{\text {nd }}$ June 2020 Date of Publish: 01 st July 2020)

\begin{abstract}
Often time, deleterious and life-threatening conditions are associated with the failure of metabolic processes to rid the blood of its numerous accumulated contents occur when too many of these waste products accumulate in the bloodstream. Fortunately, physiological bioanalytes are often compensatory flags by which the body signals a need to rid itself (blood) of these dangerous metabolites. This study was undertaken to determine lipid lowering (hypolipidemic) and anti-oxidant effects of aqueous Persea americana leaf extract on the blood, using wistar rats as experimental model. Thirty-Five (35) Wistar rats of between $140-200 \mathrm{~g}$ ) were obtained from the animal house of the Ambrose Alli University, Ekpoma, Edo State. They were then held in the animal house of the Delta State university, Abraka, Delta State, Nigeria; and grouped into seven (7) groups of five (5) rats each following a two weeks (14 days) period of acclimatization. While group A served as control; receiving normal rat chow and water only ad libitum, Groups B and $C$ were respectively treated with $200 \mathrm{mg} / \mathrm{kg}$ and $400 \mathrm{mg} / \mathrm{kg}$ of Persea leaf extract (Non-diabetic rats), groups D and E received $200 \mathrm{mg} / \mathrm{kg}$ and $400 \mathrm{mg} / \mathrm{kg}$ of Persea leaf extract after inducing Diabetes Mellitus (DM) with Alloxan monohydrate. At the end of the 28th day of administration of test substance(s), rats were sacrificed with blood samples collected via cardiac puncture and taken to the laboratory for selected antioxidant and lipid profile evaluation [Suoperoxide Dismutase (SOD), Catalase (CAT), Malondialdehyde (MDA) and Reduced Glutathione (GSH), Total cholesterol (TC), Triglycerides (TGs), Low Density Lipoproteins (LDL) and High Density Lipoproteins (HDL)]. Obtained data was then subjected into statistical test (student t-test) to compare differences in mean between groups. Results show a statistically significant decrease in TC, TGs and LDL levels for all but HDL profiles, even with incremental dosage; suggestive that Persea americana had an
\end{abstract}

2020 July Edition | www.jbino.com | Innovative Association 
hypolipidemic property. Study also observed a significant, dose-dependent decrease in antioxidant enzyme activities of experimental compared to control groups. Further studies to corroborate the findings from this work is recommended.

Keywords: Anti-Oxidant, Lipid profile, Persea Americana, Wistar rats

No: of Tables: $03 \quad$ No: of Figures: $01 \quad$ No: of References: 18

\section{Introduction}

Resulting from constant breakdowns of metabolic processes, the human body is continuously exposed to numerous free radicals that pose delirious threats to physiological homeostasis if left unremoved. It has been reported that about $5 \%$ of the inhaled oxygen gets converted into reactive oxygen species (ROS) per day [1]. These ROS bind and scavenge cellular structures to cumulatively destroy complex cellular macromolecules such as deoxyribonucleic acid (DNA), ribonucleic acid (RNA), proteins and membrane lipoproteins [1]. This is the pathogenesis and trigger for such diseases as arteriosclerosis, cancer etc. in man [2]. Often time, the excesses and damaging effects of free radicals are curtailed by way of antioxidant vitamins, which are chiefly supplied through dietary. such compounds "eat up" and rid the system of accumulated free radicals and may include such as vitamin A, C, E, carotenoids and polyphenols [2, 3].

Other than principally via food stuff, medicinal plants have been reported to be a great source of anti-oxidant,

lowering lipid levels (hypolipidemic) as well to help rid the body of such dangerous metabolytes. For this reason, the exploration of the properties of Persea americana became necessary to the research community to explore for developing natural molecules of herbal sources in the management of free radical and lipid peroxidation related ailments.

Inherent to Mexicans and Americans, Persea americana (also known as Avocado) belongs to the Lauraceae family in the taxonomy of plants. It is cultivated in the subtropical and tropical zones and averages about $8-9 \mathrm{~m}$ in height. It poses as evergreen leave $[4,5]$ with useful dicotyledonous seeds in Mexican ethno-medicinal practices. In African, it is a potent remedy for muscle, diabetes and menstrual pains and ailments $[6,7]$.

Avocado is reportedly non-toxic to humans [8]. However, its leaves, fruits and skin are poisonous to some animals; cats, dogs, cattles, goats, birds, fishes, and horses [8]. Avocado seeds, leaves and fruits contain such phytochemicals as; 
alkaloids, tannins, flavonoids, triperpenes, carotenoids, phenols, cellulose, sateroids, polyuronoids, b-galactoside and volatile oil $[9,10.11]$. Avocado contains bursts of nutrients like Vitamins ( $B, E$, and $K$ ), potassium, calcium, magnesium, iron, dietary fibres and mono-unsaturated fatty acids [12]. Its seed serves as anti-oxidants in some traditional foods due to its antioxidative properties [13]. The efficacy of its leaf in the management of infants' convulsion has been reported ${ }^{14}$. Its constituent carotenoids and tocopherol have been reported to inhibit growth of cancerous cells in the prostate gland 5 . Anti-inflammatory, analgesic, and hepatoprotective effect of the plant have also been reported in animal models [7 \& 10].

Despite the challenges and breakthroughs in the management complex medical conditions there remains a global research challenge, especially relating to free radicals, antioxidant activities and hyperlipidemia with little or no cheap availability of options to for treatments sufferers in most cases [14]. This apparently expensive and unavailable therapy has necessitated a need for a natural, efficacious and cheap alternative therapeutic product or extract. Though very little or no research work has been initiated to investigate the effect of Persea americana on lipid profile and antioxidant activity till date, Current study will therefore consider this point with a clear goal of determining the possible mechanism for which Persea americana leaf extract may potentiate its hypolipidemic and antioxidant activity at incremental doses on wistar rats over a period of four (4) weeks

\section{Aim of Study}

Current study investigated the antioxidant and lipid lowering properties of aqueous extract of Persea americana leaf on wistar rats. Specifically, the study;

i. Investigated the in-vivo free-radical scavenging (antioxidant) effect of different doses of Persea americana on wistar rats.

ii. Determined the serum lipid profile levels of Total cholesterol (TC), Triglycerides (TGs), Low Density Lipoproteins (LDL) and High Density Lipoproteins (HDL) following administration of different doses of Persea americana leaf extract on wistar rats

iii. Compared serum TC, TGs, LDD and HDL levels between normal chow fed (control) and coconut water fed wistar rats

iv. Determined the effect(s) of Avocado leaf extract on the body weights of wistar rats at different doses.

\section{Materials and Method}

\section{Study Design}

Thirty-Five (35) Wistar rats of between 140 - $200 \mathrm{~g}$ ) were obtained from the animal house of the Ambrose Alli 
University, Ekpoma, Edo State. They were then held in the animal house of the Delta State university, Abraka, Delta State, Nigeria; and grouped thereafter into seven (7) groups of five (5) rats each following a two weeks (14 days) period of acclimatization. While group A served as control; receiving normal rat chow and water ad libitum, While Groups B and C were respectively treated with $200 \mathrm{mg} / \mathrm{kg}$ and $400 \mathrm{mg} / \mathrm{kg}$ of Persea leaf extract (Non-diabetic rats), groups $\mathrm{D}$ and $\mathrm{E}$ received $200 \mathrm{mg} / \mathrm{kg}$ and $400 \mathrm{mg} / \mathrm{kg}$ of Persea leaf extract after inducing Diabetes Mellitus (DM) with Alloxan monohydrate

\section{Plant Sample Collection and Identification}

Fresh leaves of $P$. americana were obtained from local farms within study area in Abraka, Delta State. They were then authenticated by taxonomists from the Department of Botany, Faculty of Sciences, Delta State University, Abraka, Delta State, Nigeria.

\section{Preparation of Plant's extract}

leaves of $P$. americana were removed from the stem (stalk) of obtained $P$. americana bulk sun-dried for several days. It was then grounded, and $200 \mathrm{~g}$ of powder was extracted rom it using 1200 $\mathrm{ml}$ of distil water with constant stirring for 4 hours and left overnight before filtering. They were then matched into coarse powder, using mortar and pestle. $500 \mathrm{~g}$ of the powder was then soaked in 1.5 liters of distilled water for 48 hours and then filtered with cheesecloth sieve. Filtrate (aqueous extract) was then concentrated in a rotary evaporator and further dried in an oven of $3^{\circ} \mathrm{C}$ for 3 days. Yielded extract was then stored within an air-tight bottle in a refrigerator $\left(4^{\circ} \mathrm{C}\right)$ until required for the study.

\section{$\mathrm{LD}_{50}$ Determination}

Available acute toxicity study suggests that Oral medium lethal dose $\left(L_{50}\right)$ of aqueous seed extract of Persea Americana is greater than $10,000 \mathrm{mg} / \mathrm{kg}$ body weight [15]. More so, according to the American Society for Testing and Materials (1987), any chemical substance with $\mathrm{LD}_{50}$ estimate greater than 3,000$5,000 \mathrm{mg} / \mathrm{kg}$ (Oral route) could be considered of low toxicity and safe. Based on these, two concentrations $(250 \mathrm{mg} / \mathrm{kg}$ and $500 \mathrm{mg} / \mathrm{kg})$ of aqueous extract from Persea Americana were used for the experiment.

\section{Yields of extract and fractions}

The aqueous leaf extract of $P$. americana was dark green in colour after concentration to dryness. 200 and 400 $\mathrm{mg}$ of extract were stoichiometrically recovered from powdered leaves of 750 g. Weight of fractions and their yields calculated from $100 \mathrm{~g}$ of the crude extract

\section{Sample Collection}

At the end of test period, the rats were sacrificed in the morning, (using an inhalational chloroform anaesthesia) between the hours of 9 - 10 AM following an overnight fast. Each rats were then 
placed on the dorsal surface and a laparotomy incision engaged to expose their internal organs. Blood samples were then collected by cardiac puncture, using needle and syringe. Collected blood was then used to test for lipid profile [TC, TGs, LDD and HDL] levels and antioxidant enzyme [Suoperoxide Dismutase (SOD), Catalase (CAT), Malondialdehyde (MDA) and Reduced Glutathione (GSH)] activities

\section{Biochemical Assays}

\section{Determination of serum total cholesterol}

Serum total cholesterol (TC) was evaluated using Randox commercial assay kits following the methods described by Ezeigbo, (2016). One millilitre $(1 \mathrm{ml})$ of the working cholesterol reagent was added into tubes labelled blank, standard and test groups. Ten microlitres of standard cholesterol reagent, and samples were added into their respective tubes. They were mixed and allowed to stand for 10 minutes at room temperature. Absorbance of samples and standard were read with the aid of a spectrophotometer at $500 \mathrm{~nm}$. Total cholesterol level in sample was calculated using the formula

Total cholesterol in sample $(\mathrm{mg} / \mathrm{dl})=$ $\frac{\text { Absorbance of sample }}{\text { Absorbance of standard }} \times$ Concentration of standard.

\section{Determination of serum triglyceride}

Serum triglyceride was evaluated according to the methods described by
Tietz, (2014) [16]. One millilitre (1 ml) of the working triglyceride reagent was added into tubes labelled blank, standard and test groups. Ten microlitres of standard triglyceride reagent, and samples were added into their respective tubes. They were mixed and allowed to stand for 10 minutes at room temperature. Absorbance of samples and standard were read with the aid of a spectrophotometer at $500 \mathrm{~nm}$. Total cholesterol level in sample was calculated using the formula;

Total triglyceride in sample $(\mathrm{mg} / \mathrm{dL})=$ $\frac{\text { Absorbance of sample }}{\text { Absorbance of standard }} \times$ Concentration of standard

Determination of serum High Density Lipoprotein cholesterol (HDL-cholesterol):

Serum HDL-cholesterol was evaluated according to the methods developed by National Institute of Health Consensus Development Conference Statement (NIHCDCS). One hundred microliters (100 ul) of samples and standard cholesterol reagent were dispensed into test tubes containing $250 \mathrm{Ul}$ of $\mathrm{HDL}$ cholesterol precipitate (R1). The mixture was centrifuged at $4000 \mathrm{rpm}$ for 10 minutes. Thereafter, $100 \mathrm{UL}$ of samples and standard supernatants were added to another set of test tubes labelled samples and standard containing cholesterol reagent. The mixture was incubated for 10 minutes at room temperature and absorbance of standard and samples were measured against reagent blank at $500 \mathrm{~nm}$ within 60 minutes using 
Spectrophotometer. HDL-cholesterol level in sample was calculated using the formula below;

$\mathrm{HDL}$ cholesterol in sample $(\mathrm{mg} / \mathrm{dL})=$ $\frac{\text { Absornaceofsample }}{\text { Absorbance of Standard }} \times$ Concentration of standard.

Determination of serum Low Density Lipoprotein Cholesterol (LDL-cholesterol):

Low density lipoproteins (LDL) cholesterol in serum was calculated using the equation described by Friedewald's et al., (1972). The Friedewald's equation estimates the value of HDL-C using the values of total cholesterol, triglyceride and HDL-cholesterol

LDL cholesterol $(\mathrm{mg} / \mathrm{dl})=$ Total cholesterol $-\frac{\text { Triglycerides }}{5}-\mathrm{HDL}$ cholesterol.

\section{Determination of Antioxidant Enzymes Activities and lipid peroxidation}

At the end of the four (4) week period of the experiment, after all the animals have been sacrificed and blood sample obtained by cardiac puncture. Serum was the separated and subjected to laboratory procedure to determine the antioxidant enzyme activity

\section{Superoxide Dismutase (SOD) Assay}

Superoxide dismutase enzyme activity was determined according to the method of Soon and Tan (2002). By principle, the procedure measures the inhibition ability of epinephrine autooxidation. The assay was performed in
$3.0 \mathrm{ml}$ of $50 \mathrm{mM}$ sodium bicarbonate buffer (in 2 different test tubes) to which $0.02 \mathrm{ml}$ of extract was added. $0.03 \mathrm{ml}$ of the epinephrine stock solution was then added before taking absorbance readings at $480 \mathrm{~nm}$ for $3-5$ mins. A blank bereft of the sample was used for circumstantial correction. Enzymes activity will be expressed as SOD units, where one unit of SOD is defined as the quantity of enzyme needed to inhibit fifty percent $(50 \%)$ epinephrine per minute, per milligram of protein at $25^{\circ} \mathrm{C}$ and $\mathrm{pH}$ 7.8 .

\section{Catalase Assay}

The activity of the enzyme catalase was analysed according to the method by Soon and Tan (2002). The procedure measures the initial rate of $\mathrm{H}_{2} \mathrm{O}_{2}(50 \mathrm{mM})$ decomposition at $240 \mathrm{~nm}$ with the results expressed in units/mg protein where one unit is the amount of enzyme that hydrolyses 1 umol of $\mathrm{H}_{2} \mathrm{O}_{2}$ per minute and per milligram of protein at $30^{\circ} \mathrm{C}$ and $\mathrm{pH}$ 8.0. To $0.3 \mathrm{ml}(300 \mathrm{ul}$ ) of extract sample 1.8 of $30 \mathrm{mM} \mathrm{H} \mathrm{O}_{2}$ was added. Phosphate buffer was used as the blank and their absorbance reading were taken at 240 $\mathrm{nm}$ at 60 s intervals for $5 \mathrm{mins}$.

\section{Reduced Glutathione Assay}

This was determined using 5, 5dithio-bis-2-nitrobenzoic acid (DTNB) whose chemical formula is $C$ and TrisEDTA buffer with the absorbance being read at $412 \mathrm{~nm}$ (Soon and Tan, 2002). $100 \mathrm{u}$ sample was added to $1 \mathrm{ml}$ of $0.2 \mathrm{M}$ Tris-EDTA buffer, $\mathrm{pH} 8.2$. $0.9 \mathrm{ml}$ of $20 \mathrm{mM}$ 
EDTA, pH 4.7 was added $20 \mathrm{ul}$ of $10 \mathrm{mM}$ DTNB will be added and the sample will be allowed to incubate at room temperature for so $\mathrm{mm}$. The mixture was centrifuged and the absorbance of the supernatant was read against distilled water at $412 \mathrm{~nm}$. Calculation: $\mathrm{GSH}=\mathrm{OD} /$ $\mathrm{X} \mathrm{V} / \mathrm{V}$ where $\mathrm{OD}=$ absorbance; $=$ extinction coefficient; $\vee=$ total volume of reaction mixture; and $v=$ volume of sample in reaction mixture.

\section{Malondialdehyde (MDA) Assay}

Malondialdehyde has been identified as an invention of lipid peroxidation that reacts with thiobarbituric acid to give red specie with absorbance at $535 \mathrm{~nm}$ (Soon and Tan, 2002). $1 \mathrm{ml}$ of the extract sample was combined "l with $2.0 \mathrm{ml}$ of trichioroacetic acid $(15 \% \mathrm{w} / \mathrm{v})$ thiobarbutric acid $(0375 \% \mathrm{w} / \mathrm{v})$ hydrochloric acid $(0.25 \mathrm{~N})$ and mixed thoroughly. The solution was later heated for $15 \mathrm{~mm}$ in a water bath at boiling capacity. After cooling the solution, the flocculent precipitate was removed by simple centrifugation at 1000 rev for $10 \mathrm{~mm}$. The absorbance of the sample was determined at $535 \mathrm{~nm}$ against a blank that contains the entire reagents minus the sample. The MDA concentration of the sample was calculated using an extinction coefficient of $1.56 \times 10^{-5} \mathrm{M}^{-1} \mathrm{Cm}^{-1}$. Calculation: MDA $(\mathrm{nmol} / \mathrm{ml}) \quad O D / \Sigma \times V / \mathrm{v}$ where $O D=$ absorbance (optical density) of sample; $\Sigma=$ molar extinction coefficient; $\vee=$ total volume of reacting sample; and $v=$ volume of the sample.

\section{Statistical Analysis}

Data obtained from the study were analysed with Graph pad Prism (version 8). Results were presented as Mean \pm Standard error of mean (SEM) of sample replicates. Raw data were subjected to one way analyses of variance (ANOVA) followed by post hoc Tukey's test. Pvalues < 0.05 was considered to be statistically significant. 


\section{Results}

TABLE 1: Effect of Persea americana leaf extract on body weight

\begin{tabular}{l|c|c|c|c|c}
\hline Treatment & Group A & Group B & Group C & Group D & Group E \\
& & & & & \\
\hline Initial & $\begin{array}{c} \pm 4.60 \\
\end{array}$ & 133.23 & $\begin{array}{c}133.10 \\
\pm\end{array}$ & $\begin{array}{c}182.10 \\
\pm\end{array}$ & $\begin{array}{c}134.23 \\
\pm\end{array}$ \\
& 4.23 & 2.21 & 4.11 & 7.96 & 1.24 \\
\hline Final & 162.01 & 165.12 & 151.21 & 132.68 & 137.47 \\
& \pm .01 & $3.02^{*}$ & $5.33^{*}$ & $4.35^{*}$ & 2.25 \\
\hline $\begin{array}{l}\text { \% } \Delta . i n \\
\text { body } \\
\text { weight }\end{array}$ & 27.83 & 19.21 & 17.58 & -27.34 & -8.34 \\
& & & & & \\
\hline
\end{tabular}

Values are expressed as Mean \pm SEM, $n=5 . *^{+}=$statistically significant increase, ${ }^{*}=$ statistically significant decrease at $p<0.05$ compared to control (Group A)

TABLE 2: Effect of Persea americana aqueous leaf extract on Lipid profile

\begin{tabular}{l|c|c|c|c|c}
\hline & Group A & Group B & Group C & Group D & Group E \\
& & & & & \\
\hline \multirow{2}{*}{ TC } & 145.23 & 164.34 & 163.44 & 174.43 & 132.24 \\
& \pm & \pm & \pm & \pm & \pm \\
& 9.47 & 10.57 & 10.35 & $10.23^{*}$ & $9.12^{-}$ \\
\hline \multirow{2}{*}{ TAG } & 146.34 & 145.33 & 145.42 & 171.32 & 123.32 \\
& \pm & \pm & \pm & \pm & \pm \\
& 0.36 & 0.57 & 0.46 & $0.43^{*+}$ & $0.45^{*}$ \\
\hline \multirow{2}{*}{ HDL } & 133.91 & 135.43 & 158.24 & 159.23 & 134.45 \\
& \pm & \pm & \pm & \pm & \pm \\
& 0.33 & 0.23 & $0.54^{*}$ & $1.13^{*}$ & 0.54 \\
\hline \multirow{2}{*}{ LDL } & 140.43 & 148.04 & 155.44 & 141.43 & 144.54 \\
& \pm & \pm & \pm & \pm & \pm \\
& 2.31 & $2.32^{*}$ & $2.12^{*}$ & 2.23 & 1.12 \\
\hline
\end{tabular}

Values are expressed as Mean \pm SEM, $n=5 . *^{*}=$ statistically significant increase, ${ }^{*}=$ statistically significant decrease at $p<0.05$ compared to control (Group A) 
TABLE 3: Effect of Persea americana aqueous leaf extract on Antioxidant Activities

\begin{tabular}{l|c|c|c|c|c}
\hline & Group A & Group B & Group C & Group D & Group E \\
& & & & & \\
\hline \multirow{3}{*}{ SOD } & 25.23 & 12.23 & 20.57 & 21.34 & 26.12 \\
& \pm & \pm & \pm & \pm & \pm \\
& 3.24 & $3.45^{*^{-}}$ & $3.13^{*^{-}}$ & $3.23^{*^{-}}$ & 3.22 \\
\hline \multirow{3}{*}{ MDA } & 2.50 & 1.33 & 1.32 & 1.47 & 141 \\
& \pm & \pm & \pm & \pm & \pm \\
& 0.36 & $0.57^{*^{+}}$ & $0.46^{*^{+}}$ & $0.43 *^{+}$ & $0.45^{*^{+}}$ \\
\hline \multirow{3}{*}{ CAT } & 65.23 & 43.25 & 43.23 & 49.15 & 42.35 \\
& \pm & \pm & \pm & \pm & \pm \\
\hline \multirow{3}{*}{ GSH } & 0.08 & $0.96^{*^{-}}$ & $0.86^{*^{-}}$ & $1.54 *^{-}$ & $0.35^{*^{-}}$ \\
\hline & 80.24 & 25.75 & 55.22 & 51.22 & 57.43 \\
& 2.23 & $2.54 *^{-}$ & $2.46^{*^{-}}$ & $2.75 *^{-}$ & \pm \\
\hline
\end{tabular}

Values are expressed as Mean \pm SEM, $n=5 . *^{+}=$statistically significant increase, $*^{-}=$statistically significant decrease at $p<0.05$ compared to control (Group A)

Figure I: Comparative Durational Effect of Persea americana aqueous leaf extract on Body weights between groups

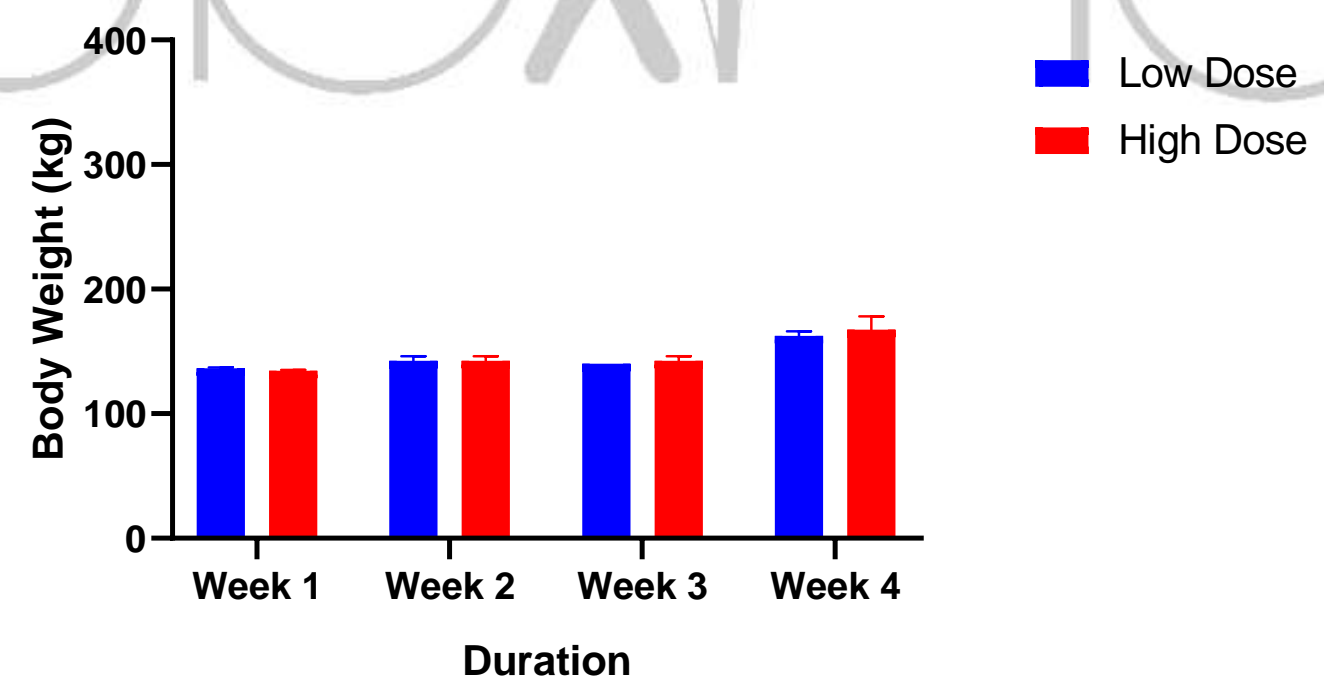

Discussion

Potential bioactive components reportedly exist in plant extracts, making them a cheap, readily available and efficacious choice for people suffering numerous conditions like Diabetes Mellitus (DM) and its related complications [17]. Plant extracts have also been used by man 2020 July Edition | www.jbino.com | Innovative Association 
over a long time for the treatment of aging and cellular damages occasioned be increased free radicals [17].

In this study, Alloxan monohydrate (a diabetogenic agent) was used to induce DM in animal (wistar rats) models. Persia americana leaf extract (aqueous) was then administered at different doses $(200$ and $400 \mathrm{mg} / \mathrm{kg}$ body weight) for a duration of four weeks (28 days), following which serum was obtained and analysed for body weight changes and selected antioxidant enzyme activities as well as lipid profile levels.

A careful observation of the result from this study (table I) shows a statistically significant decrease in body weight for diabetic rats treated with 200 and 400 $\mathrm{mg} / \mathrm{kg}$ body weight of $P$. americana extract (groups $D$ and $E$ ) respectively as compared to non-diabetic, extract treated animals. This may have been caused by the rapid loss of muscle mass and adipocytes occasioned by the damaging effect of Tissue Necrotic Factors (TNF) and excessive breakdown of protein and fatty acids [18]. This may result in a significant loss of calories via glucose excretion, causing severe weight lost in spite of increased appetite as seen in table I. however, the reverse was the case for non-diabetic extract treated groups B and C. here, there was an adequate interaction of the bioactive component to cause lipogenesis and deposition of fatty acids (Obviously as triglycerides) in the adipose tissues. Thus, the extract treated rats presented with an appreciable weight gain compared with diabetic control group. This observation was in line with earlier reports of Mohammed et al., (2006) who reported that weight gain in non-diabetic rats may be due to proper utilization of food and fluid influenced by $P$. americana extracts [17]. The medicinal use of $P$. americana has been mentioned in several texts. These properties of it characterize its usefulness as "good for heart and cardiovascular system" Table 3 of our result shows the effect of $P$. americana on Reduced Glutathione (GSH) level in wistar rats fed with increasing doses of extract for four weeks. Here, a statistically significant decrease is observed for GSH level in $P$. americana low dose treated groups, whereas, other groups (high dose treated) showed an insignificant change compared to control. Also, comparison of extract effect on diabetic group revealed a significant increase in GSH level as against non-diabetic treated groups. This implicates $P$. americana to be efficacious with increasing dose. Also catalase activity returned a significant decrease in all treated groups but control, implicating that treatment all doses in diabetic rats significantly improved SOD and GSH level in diabetes [3].Theoretically, oxidative stress is a known equalizer for the generation of ROS (super- oxide anion) and the antioxidant systems that plays out to protect the body; such as superoxide dismutase (SOD). Antioxidants enzymes are involved in the elimination of ROS include SOD, CAT and GSH, respectively. Data from this present study showed a decrease in the activities of all measured antioxidants enzymes in rats. This thus indicates a weakness in the antioxidant defence system. However, 
administration of $P$. americana increased the activities of the anti- oxidant enzymes. Since oxidative stress is a key aspect of the pathophysiology of DM, P. americana might thus be therapeutically effective in lowering the level of oxidative damage to tissues, thus, may be beneficial to DM management (Maritim et al., 2003). Available reports also assert that exogenous administration of antioxidants is protective to diabetic health as intracellular enzymes like SOD and CAT may help improve the antioxidant defence system to better scavenge on ROS due to tissue damage. SOD purifies superoxide radicals and converts them to $\mathrm{H}_{2} \mathrm{O}_{2}$ for water formation via the Catalase (CAT) enzyme. This process decreases GSH that is often related to the pathogenesis of DM Nevin and Rajamohan (2006). The results from this study is in agreement with that of Nevin and Rajamohan (2006)

Current study also revealed a statistically significant increase in serum Total Cholesterol levels (at $p<0.05$ ) for $P$. americana fed, diabetic wistar rats (irrespective of dose) as compared with control (Table 2), even though, a significant decrease was seen for same group compared with $P$. Americana fed, non-diabetic control (groups B and C) rats.

Table 2 also shows a statistically significant decrease $(p<0.05)$ in LDH and HDL levels across groups irrespective of $P$. Americana dosage and duration of administration, suggestive that $P$. Americana extract caused a significant improvement in serum LDH level (bad cholesterol). This finding concurs with that of Dosumu et al., (2010) [3] who had earlier reported a significant difference in Total Cholesterol and LDL levels for experimental groups than control rats.

\section{Conclusion}

Results from this study has shown that Persea americana extract (leaf) administration may increase antioxidant enzyme activity in the blood, while lowering LDL and cholesterol levels in diabetic rats. This is a protective mechanism that may help improve the antioxidant defense system of the body with a corresponding hypolipidemic outcome as well.

\section{References}

1. Matkovics B., Kotorman M., Varga I.S. (2007) Pro, antioxidant studies in the blood of type 2 diabetic patients. Acta. Physiol. Hung.; 85(2):107-12.

2. Nevin, K.G. and Rajamohan, T. (2006) Virgin coconut oil supplemented diet increases the antioxidant status in rats. Food Chemistry, 99, 260-266.

3. Dosumu Olufunke O., Akinola Oluwole B., Akang Edidiong N. (2012) Alcohol-induced testicular oxidative stress and cholesterol homeostasis in rats - The therapeutic potential of virgin coconut oil. Middle East Fertility 
Society Journal Volume 17, Issue 2, Pages 122-128

4. Concannon, P., Gogolin-Ewens, K.J., Hinds, D.A., Wapelhorst, B., Morrison, V.A and Stirling B (2013). A second generation screen of the human genome for susceptibility to insulin-dependent diabetes mellitus. Nature Genetics: 19: 292-296.

5. Adeboye, J.O., Fajonyomi, M.O., Makinde, J.M. \& Taiwo, O.B. (1999). A Preliminary Study on the hypotensive activity of Persea Americana leaf extracts on anaesthetized normotensive rats. Fitoterapia;70:15-20.

6. Adeyemi, 0.0., Okpo, S.O. \& Ogunti, 0.O. (2002). Analgesic and anti-inflammatory effects of the aqueous extract of leaves of Persea Americana Mill (Lauraceae), Fitoterapia;70:375380.

7. Ozolua, R. I., Anaka, O.N., Okpo, S.O. \& Idogun, S.E. (2009). Acute and Subacute Toxicological Assessment of the Aqueous extract of Persea Americana Mill (Lauraceae) in Rats. Afr J Tradit Complement Alter Med.; 6(4):573578.

8. Ding, H., Chin, Y.W., Kinghorn, A.D. \& D'Ambrosio, S.M. (2007). Chenmopreventive characteristics of Avocado fruit. Semi Cancer Biol.; 17:386-394.

9. Kawagishi, H., Fukumoto, Y., Hatakeyama, M., He, P., Arimoto, H. \& Matsuzawa, T. (2001). Liver injury suppressing compounds from Avocado (Persea Americana). J Agric Food Chem.; 49:2215-2221.

10. Olaete, J.A., Schwartz, M., Undurraga, P. \& Contreas, S. 2007. Use of Hass Avocado (Persea Americana Mill) seed as a processed product. Proceedings of the VI World Avocado Congress: 18.

11. Naveh, E., Werman, M.J., Sabo, E. and Neeman I. (2002). "Defatted Avocado pulp reduces body weight and total hepatic fat but increases plasma cholesterol in male rats". J. Nutr.; 131(7):20152018.

12. Nneli R. O., Qoyike A. (2000). Antiallergic effects of coconut (cocos nucifera) extract in rats.Poytother Res 22:970 - 972.

13. Dolezal K. (2006). Preparation and biological activity of 6benzylaminopurine derivatives in plants and animal ancer cells. Bioorgmed chem. 14:875-877

14. Ojewole, J.A. and Amabeoku G.J. (2006). Anticonvulsanteffect of 
Persea Americana Mill (Lauraceae)(Avocado) leaf aqueous extract in mice. Phytother Res.; 14:20-25.

15. Lorke, D. (1983). A new approach to practical acute toxicity. Archives of Toxicology. 53:275-289.

16. Tietz, N.W. (2014). Clinical guide to Laboratory tests, Second edition W.B. Saunders Company, Philadelphia, USA 554-556.

17. Mohammed, B., Adderahim, Z., Hassane, M., Abdulhafid, T. \& Abdulkhahaleg, L. (2006). Medical plants with potential antidiabetic activity. A review of ten year herbal medicine research (1999-2009). Int. J .Diabet Metab.; 14:1-25.

18. Tanko, Y., Sada, N.H., Mohammed, K.A., Jimoh, M., Yerima, M. \& Mohammed, A. (2013). Effect of ethanolic extract of Caralluma Deizielli on serum electrolyte levels on fructose-induced diabetic wistar rats. Am. Biol. Res.; 4:157-161.

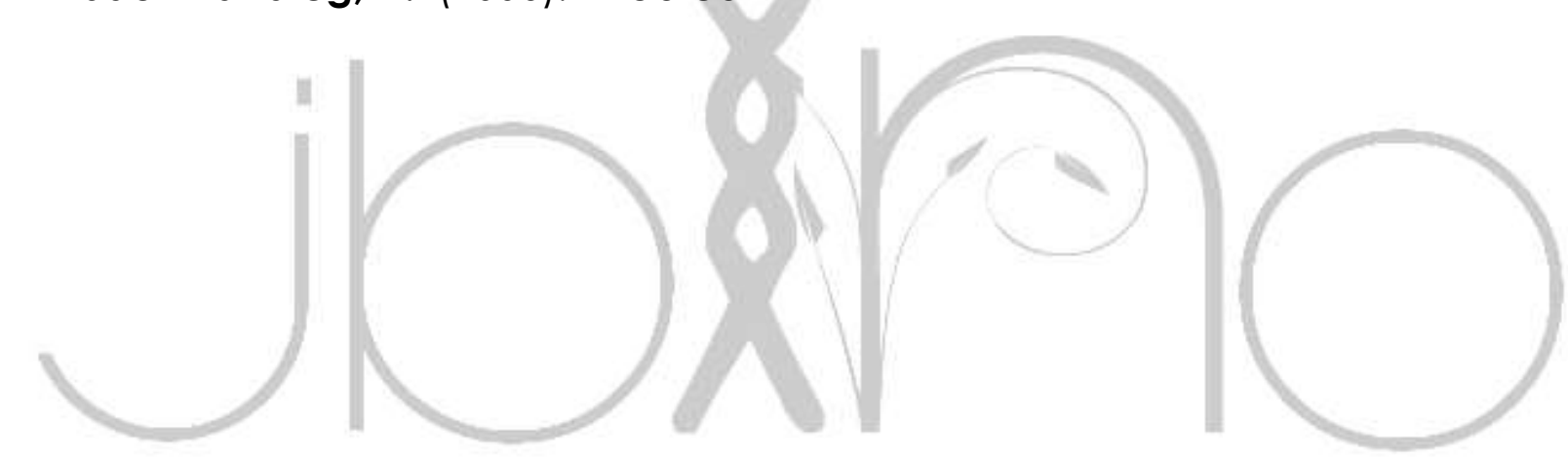

